Research Article

Joanna Zięba* and Izabela Skrzypczak

\title{
Analysis of reliability of compressed masonry structures
}

https://doi.org/10.1515/eng-2020-0055

Received Jul 12, 2019; accepted Nov 15, 2019

\begin{abstract}
Designing masonry structures or any other structures involves ensuring an adequate level of safety. This is done by applying the appropriate set of partial factor for strength and partial factors for actions in accordance with the recommendations of the Eurocodes. The paper presents an analysis of the reliability of a compressive masonry structure on the example of a wall fragment made of silicate blocks. The relationship between partial factors applied to actions in various configurations and factors for the compressive strength of masonry was investigated. The analyses consisted in determining the reliability index $\beta$ using the First Order Reliability Method (FORM). The results are presented in diagrams with reference to different construction classes execution of works, as well as different reliability classes from RC1 to RC3.
\end{abstract}

Keywords: masonry structures, compressive strength of masonry, reliability of construction, safety

\section{Introduction}

Technological progress in masonry structures have resulted in the creation of competitive solutions in both execution and design, which forces the need for an ever deeper recognition of this type of construction.

Proper design of a masonry structure is based on the use of a set of appropriate standards, defining not only the specifics of the type of the designed structure, but also, for example, ensuring an adequate level of safety. \footnotetext{
*Corresponding Author: Joanna Zięba: Department of Build-
ing Structures, Faculty of Civil Engineering and Environmental ^Corresponding Author: Joanna Zięba: Department of Build-
ing Structures, Faculty of Civil Engineering and Environmental Engineering, Rzeszow University of Technology, Poland; Email: j.zieba@prz.edu.pl

Izabela Skrzypczak: Department of Geodesy and Geotechnics, Faculty of Civil Engineering and Environmental Engineering, Rzeszow University of Technology, Poland; Email: izas@prz.edu.pl
} ๖ Open Access. (c) 2020 J. Zieba and I Skrzypczak, published by De Gruyter Attribution 4.0 License

\subsection{Problematics of compressive strength of masonry}

The basic strength case occurring in masonry structures is compression in the direction perpendicular to the support welds [3]. The characteristic compressive strength of masonry $\mathrm{f}_{k}$ should be determined on the basis of the test results, because the masonry is a typical material with anisotropic properties, the strength of which consists of both the strength of the masonry element itself and the mortar. Analysing the load-bearing capacity of a masonry structure, the problem is simplified, treating the masonry as a homogeneous material with the same strength properties at each of its points [1]. When determining the strength of masonry, pay attention to: normalised mean compressive strength of a masonry units - which is declared by the manufacturer; a group of masonry unit; the product category and compressive strength of masonry mortar; in the case of ordinary and lightweight mortars $[9,10]$. Referring to EC6 [3] and the polish national annex, we can find 4 modifications of the presented formula. To ensure an adequate safety margin, the characteristic value of strength should be transformed into a design value using an appropriate safety factors, which in masonry structures is called $\gamma_{M}$

$$
\gamma_{M}=\gamma_{R d} \cdot \gamma_{m}
$$

where:

$\gamma_{m}$ - partial factor for materials, including uncertainties about geometry and modelling; $\gamma_{R d}$ - partial factor taking into account the uncertainty of the theoretical calculation model of the structure.

Determining the value of $\gamma_{R d}, \gamma_{m}$ - or directly $\gamma_{M}$ are problematic. The Eurocodes give recommendations for "setting these values according to the scope of application of research results". These are values from the NDP group - nationally dermided parameters - reserved to be determined by the standard national organizations in consultation with the competent national authorities of the EU Member States. The task is difficult because it connects with the level of construction safety required in the country. 
Table 1: The exemplary values of the partial factor $\gamma_{m}$ according to the polish annex EC6 [3]

\begin{tabular}{lllc}
\hline & Material & \multicolumn{2}{c}{$\begin{array}{c}\text { Classes } \\
\text { execution of } \\
\text { works }\end{array}$} \\
\cline { 3 - 4 } & & A & B \\
\hline A $\quad \begin{array}{l}\text { masonry made with units of cate- } \\
\text { gory I, designed mortar }\end{array}$ & 1.7 & 2.0 \\
B $\quad \begin{array}{l}\text { masonry made with units of cate- } \\
\text { gory I, prescribed mortar }\end{array}$ & 2.0 & 2.2 \\
C $\quad \begin{array}{l}\text { masonry made with units of cate- } \\
\text { gory II, any mortar }\end{array}$ & 2.2 & 2.5 \\
\hline
\end{tabular}

Values of the partial factor are determined for two classes execution of works, class A execution of works when the masonry works are performed by a duly trained team under supervision master mortar, and class B execution of works - when the conditions defining the class A are not met.

\subsection{Reliability of constructions}

Designing both masonry and any other construction involves ensuring an adequate level of safety. Determination of the level of safety begins with qualifying the construction to the appropriate class of consequences. ECO [4] distinguishes three classes of consequences, which in turn correspond to three classes of reliability. Reliability, unlike safety, is a measurable feature, expressed, for example, by the reliability index of the Hasofer - Linda $\beta$. This index was defined as the minimum value for the class from RC1 to RC3 and for two reference periods. Generally speaking, the application of the set of coefficients binding in Eurocodes determines the reliability of the construction at the RC2 class level. However, in the other cases, i.e. designing a structure in the RC1 or RC3 class, the ECO [4] is a simplification for us. ECO [4] recommends the use of factor for actions. The standard contains a record that it is not recommended to modify the value of material partial factors. Table 2 presents the factor for actions recommended according to ECO [4].

Table 2: $\mathrm{K}_{F I}$ factor for actions

\begin{tabular}{cccc}
\hline $\mathrm{K}_{F I}$ factor for actions & \multicolumn{3}{c}{ Reliability class } \\
\cline { 2 - 4 } & $\mathrm{RC} 1$ & $\mathrm{RC} 2$ & $\mathrm{RC} 3$ \\
\hline $\mathrm{K}_{F I}$ & 0.9 & 1.0 & 1.1 \\
\hline
\end{tabular}

When designing and assessing the reliability of a structure and its elements, you can use the following methods: deterministic (level 0), semi-probability (level I), simplified probabilistic (level II), probabilistic (level III) [12].

\section{Procedure for verification of partial factors}

The properties and quality of materials affect the assessment of the reliability of building structures. The influence of material partial factors for masonry on the level of reliability was evaluated on the basis of analyses carried out for a masonry fragment, taking into account the class execution of work and the recommended standard partial material factors. This effect for masonry structures, designed according to EC6, was determined by determining the reliability index. This study limits the considerations to the recommended by the ECO [4] and PN-ISO 2394 [11] standards of reliability index $\beta$ using the First Order Reliability Method (FORM).

A properly designed construction is one for which dependence is fulfilled:

$$
R_{d} \geq E_{d}
$$

where:

$R_{d}$ - design value of the resistance, $E_{d}$ - design value of effect of action.

In the work with regard to the analysed structural element, only permanent actions and one variable action are considered. In order to determine the average of actions, the coefficient of variation for a constant action of $v=0,10$ and for a variable action of $v=0,20$ [12] was assumed. The assumed variable action in the conducted analyses is the variable action in buildings.

Permanent and variable actions according to ECO [4] can be combined with the following relationships: $6.10 \mathrm{a}$ (3), 6.10b (4), 6.10 (5).

$$
\begin{aligned}
E_{d} & =\sum_{j \geq 1} \gamma_{G, j} G_{k, j} "+" \gamma_{P} P ”+" \gamma_{Q, 1} \psi_{Q, i} Q_{k, 1} \\
& =" \sum_{i>1} \gamma_{Q, i} \psi_{0, i} Q_{k, i}
\end{aligned}
$$

$$
\begin{gathered}
E_{d}=\sum_{j \geq 1} \xi_{j} \gamma_{G, j} G_{k, j}{ }^{\prime}+{ }^{\prime} \gamma_{P} P ”+{ } \gamma_{Q, 1} Q_{k, 1} \\
{ }_{+}{ } \sum_{i>1} \gamma_{Q, i} \psi_{0, i} Q_{k, i}
\end{gathered}
$$




$$
\begin{gathered}
E_{d}=\sum_{j \geq 1} \gamma_{G, j} G_{k, j} "+\gamma_{P} P ”+" \gamma_{Q, 1} Q_{k, 1} \\
{ }^{+}{ } \sum_{i>1} \gamma_{Q, i} \psi_{0, i} Q_{k, i}
\end{gathered}
$$

where:

$\mathrm{G}_{k}$ - characteristic value of a permanent action, $\mathrm{Q}_{k}$ - characteristic value of a variable action, $\mathrm{P}$ - relevant representative value of a prestressing action, $\gamma_{P}-$ partial factors for prestressing actions

Values of partial factors for actions contained in equations, according to ECO [4], $\gamma_{G}=1,35, \xi=0,85, \gamma_{Q}=1,5$, $\psi_{0,1}=0,7$.

The designed bearing capacity of a structural element is determined by the adopted calculation model and material properties. Characteristic values $\left(\mathrm{f}_{k}\right)$ of material or product properties are values corresponding to the assumed probability of not exceeding them in a theoretically unlimited series of tests. Usually, they correspond to the specified quantile of the adopted statistical distribution of a specific material or product property. Assuming a normal distribution, the characteristic value can be determined by using the relationship:

$$
f_{k}=f_{m}-1,645 \cdot \sigma=f_{m} \cdot(1-1,645 \cdot v)
$$

where:

$f_{m}$ - medium material strength; $\sigma / v$ - standard deviation / coefficient of variation of material strength.

The procedure for the reliability analysis, in relation to the class execution of work and partial factors recommended in ECO [4] was carried out according to the following algorithm [8]:

1. The designed value of the resistance was calculated: $R_{d}$,

2. It has been assumed that the designed value of the resistance is equal to the designed value of effect of actions: $R_{d}=E_{d}$,

3. The relation between permanent and variable actions according to the formula was defined:

$$
\chi=Q_{k} /\left(G_{k}+Q_{k}\right)
$$

4. The effect of actions has been transformed into the characteristic values for the effect of constant and variable actions according to the appropriate relationship:

$$
\begin{aligned}
& G_{k}=E_{d} /\left(\gamma_{G}+\gamma_{Q} \cdot \chi /(1-\chi)\right) \\
& Q_{k}=E_{d} /\left(\gamma_{G} \cdot(1-\chi) / \chi+\gamma_{Q}\right)
\end{aligned}
$$

5. Statistical parameters (mean and coefficient of variation) were again specified for random variables depending on material properties and geometrical features.

6. The probabilities of exceeding the ultimate limit states and the corresponding reliability indices for individual action factors belonging to the range $\chi \in$ $(0 ; 1,0)$ were estimated.

\section{Analysis of reliability of exemplary masonry structure}

The paper presents an analysis of reliability for the inner masonry of the ground floor of a multi-storey building made of silicate blocks. Material has normalised mean compressive strength of a masonry unit $\mathrm{f}_{b}=15,0 \mathrm{MPa}$. The wall has been made on the lightweight masonry mortar. The characteristic compressive strength of masonry for this structure is determined by the formula:

$$
f_{k}=K f b^{0,85}=0,45 \cdot 15^{0,85}=4,50 \mathrm{MPa}
$$

$K$ - for a group 2 of masonry elements and general purpose mortar $\mathrm{K}=0,45[3]$

The wall analysis was carried out in two variants: by adopting the class execution of works $\mathrm{A}$ and in the next step $B$. The design compressive strength of masonry made in class A, for which the partial factor $\gamma_{m}=1,7$ is $f_{d}=$ 2, $65 \mathrm{MPa}$. The design compressive strength of masonry made in class B, for which the partial factor $\gamma_{m}=2,0$ is $f_{d}=2,25 \mathrm{MPa}$. Due to the fact that the works' classes execution of works refer to different workmanship, different coefficients of variation for the compressive strength of masonry were adopted for these classes. Referring to literature [2], the coefficient of variation for the compressive strength of masonry $v=0,19$ was assumed for class A. For class B, the coefficient of variation for the compressive strength of the masonry wall $v=0,26$ was assumed. The values have been selected individually from the range specified in the literature [2]. For the presented element, the state of limit function has been built as follows:

$$
Z=\left(1-2 e_{i} / t\right) \cdots f_{d}-E_{d}
$$

where:

$e_{i}$ - eccentricity of a wall [mm], $t$ - thickness of a wall [mm], $l$ - length of a wall (for this example $l=1000[\mathrm{~mm}]$ )

On the basis of the prepared database, the probabilities of exceeding the ultimate limit states and the corresponding reliability indices for individual action factors 
have been estimated. An important element of the example solution was determination of random variables occurring in the function of the limit state of the element being analysed (Table 3). In determining the appropriate probability distributions, it was suggested to use literature that is rich in items concerning, for example, the determination of the probability density function for the compressive strength of masonry [2]. Geometric parameters such as wall thickness and eccentricity were adopted as random variables with a normal distribution and a coefficient of variation of $5 \%$. The use of normal distribution is the right approach for permanent interactions, while for variable loads the Gumbel distribution is used [11].

Table 3: Parameters of random variables occurring in the limit state function

\begin{tabular}{|c|c|c|c|c|c|}
\hline \multicolumn{2}{|c|}{$\begin{array}{l}\text { Random } \\
\text { variable }\end{array}$} & \multirow{2}{*}{$\begin{array}{r}\text { Density } \\
\text { function }\end{array}$} & \multirow{2}{*}{$\begin{array}{c}\begin{array}{c}\text { Average } \\
\text { value }\end{array} \\
250\end{array}$} & \multirow{2}{*}{$\begin{array}{c}\begin{array}{c}\text { Coefficient } \\
\text { of } \\
\text { variation }\end{array} \\
0.05\end{array}$} & \multirow{2}{*}{$\begin{array}{l}\text { Unit } \\
{[\mathrm{mm}]}\end{array}$} \\
\hline & & & & & \\
\hline $\mathrm{f}_{m}$ & A & LN & 6.54 & 0.19 & {$[\mathrm{MPa}$} \\
\hline & B & & 7.86 & 0.26 & {$[\mathrm{MPa}$} \\
\hline & & Normal & 25 & 0.05 & {$[\mathrm{~mm}]$} \\
\hline & & Normal & $\mathbf{G}_{m}$ & 0.10 & {$[\mathrm{kN}]$} \\
\hline & & Gumbel & $\mathrm{Q}_{m}$ & 0.20 & {$[\mathrm{kN}]$} \\
\hline
\end{tabular}

First, an attempt was made to determine the level of safety for the RC2 class. The results of the analyses performed are presented in Figure 1 and Figure 2.

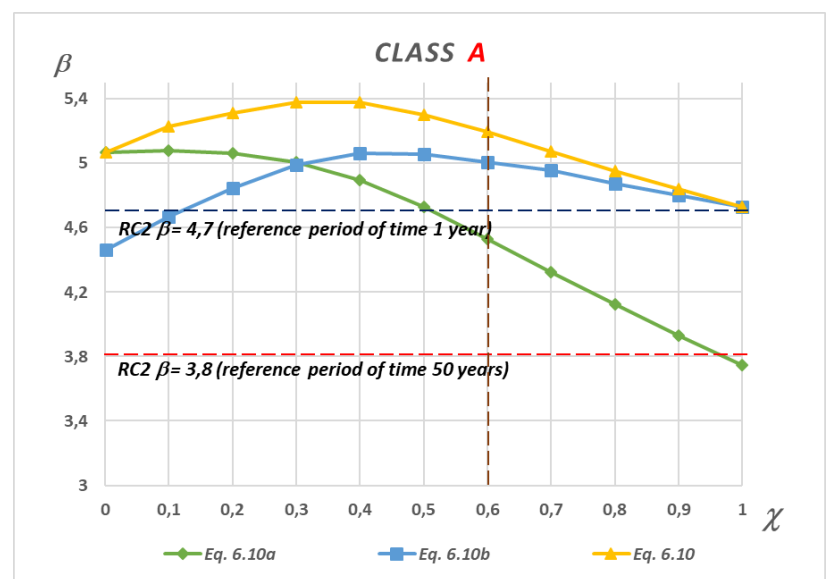

Figure 1: Reliability coefficient curves $\boldsymbol{\beta}$ and load factor $\boldsymbol{\chi}$ for the class $A$ execution of works and three different combinations of standard coefficients (formulas: 6.10a, 6.10b, 6.10) - reliability class $\mathrm{RC2}$

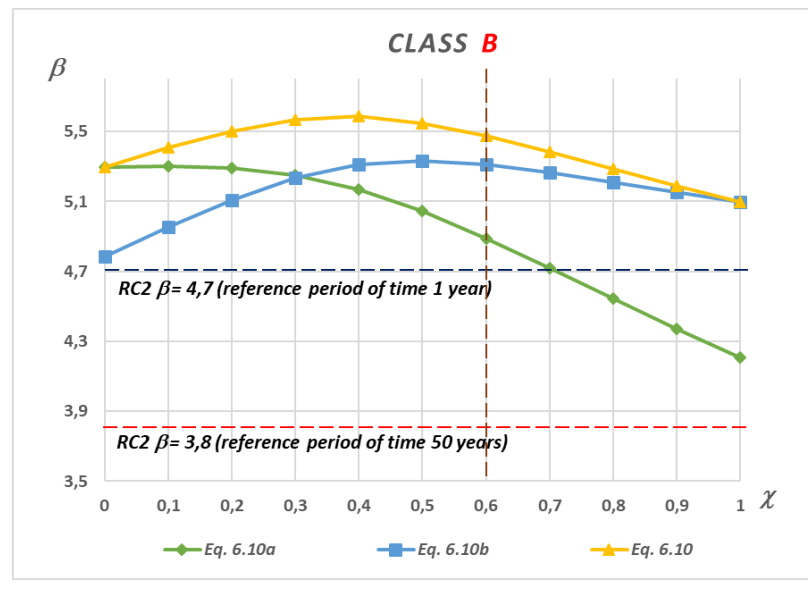

Figure 2: Reliability coefficient curves $\boldsymbol{\beta}$ and load factor $\boldsymbol{\chi}$ for the class $B$ execution of works and three different combinations of standard coefficients (formulas: 6.10a, 6.10b, 6.10) - reliability class RC2

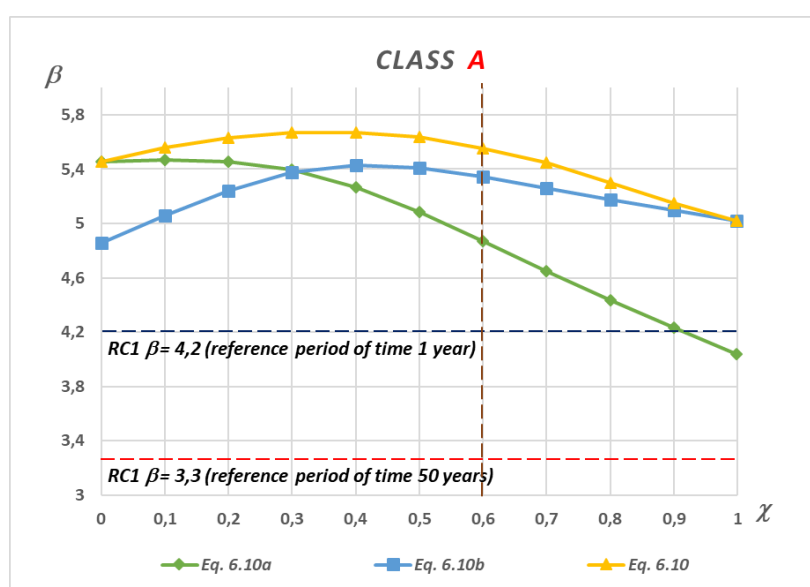

Figure 3: Reliability coefficient curves $\boldsymbol{\beta}$ and load factor $\chi$ for the class $A$ execution of works and three different combinations of standard coefficients (formulas: $6.10 \mathrm{a}, 6.10 \mathrm{~b}, 6.10$ ) - reliability class RC1

Subsequent similar analyses were carried out designing the construction in the order of $\mathrm{RC} 1$ and $\mathrm{RC} 3$ respectively. As recommended by ECO [4], only factors for actions were used. The analyses for the reliability class RC1 are presented in Figure 3 and Figure 4.

The situation looks a bit different in relation to the RC3 class, this time the factor 1.1 for actions was applied according to the norm - Figure 5, Figure 6.

In the presented example, specific values of the coefficient of variation for strength in the range specified by literature were assumed as already mentioned above. However, these were values that were randomly selected in some way. Therefore, it was necessary to check how much the 


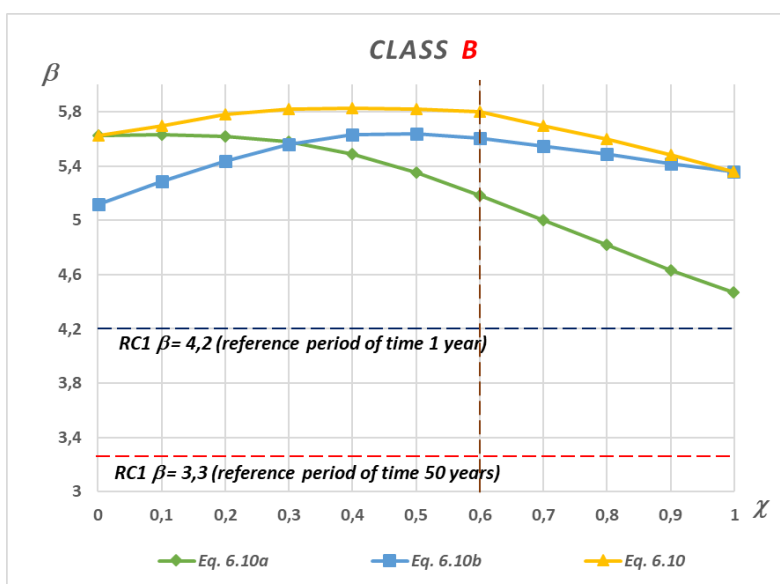

Figure 4: Reliability coefficient curves $\boldsymbol{\beta}$ and load factor $\boldsymbol{\chi}$ for the class $B$ execution of works and three different combinations of standard coefficients (formulas: $6.10 \mathrm{a}, 6.10 \mathrm{~b}, 6.10$ ) - reliability class RC1

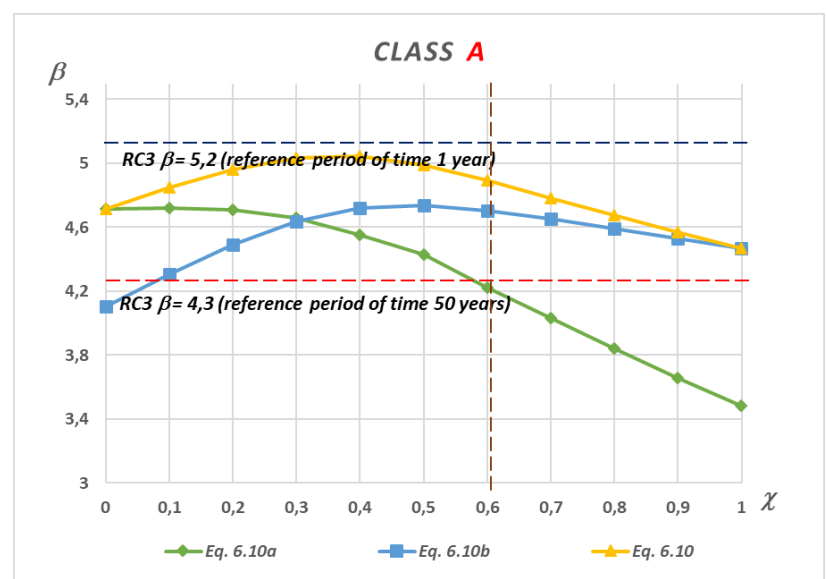

Figure 5: Reliability coefficient curves $\boldsymbol{\beta}$ and load factor $\boldsymbol{\chi}$ for the class $A$ execution of works and three different combinations of standard coefficients (formulas: $6.10 \mathrm{a}, 6.10 \mathrm{~b}, 6.10$ ) - reliability class $\mathrm{RC} 3$

reliability index is sensitive to individual variables occurring in the function of the limit state.

As you could guess (Figure 7), the greatest impact on the element's reliability level is the compressive strength of masonry. Going further along this trail, a surface chart (Figure 8), was generated presenting the ratio of reliability index, load factor and different coefficient of variation for strength. A coefficient of variation in strength in the range from $5 \%$ to $30 \%$ was assumed. The relationship was determined for one for the formula 6.10a.

It was noticed that regardless of the variability of strength, safety in relation to the RC2 class is ensured with a significant margin.

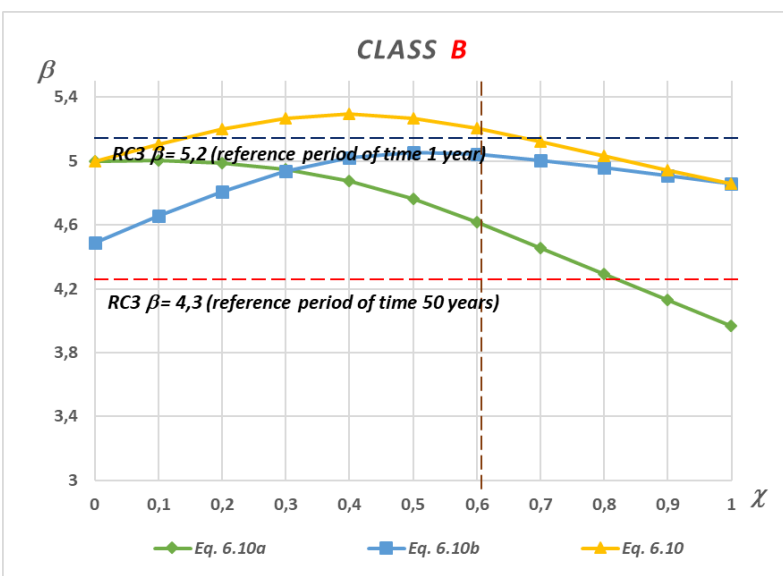

Figure 6: Reliability coefficient curves $\boldsymbol{\beta}$ and load factor $\chi$ for the class $B$ execution of works and three different combinations of standard coefficients (formulas: 6.10a, 6.10b, 6.10) - reliability class RC3

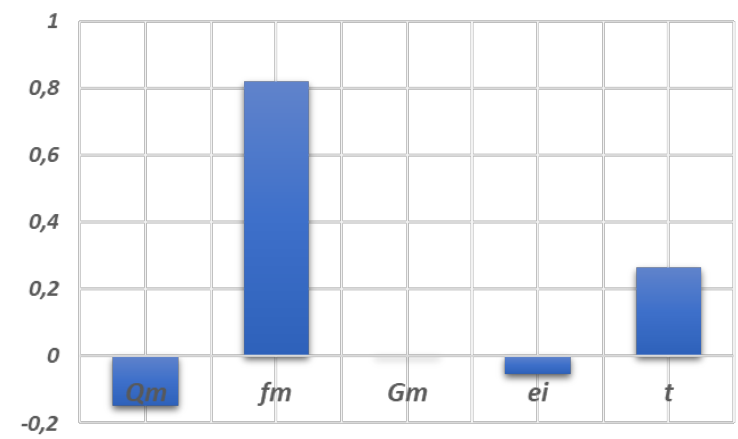

Figure 7: Chart of sensitivity of the reliability index to random variables of the limit state function - reliability class RC2

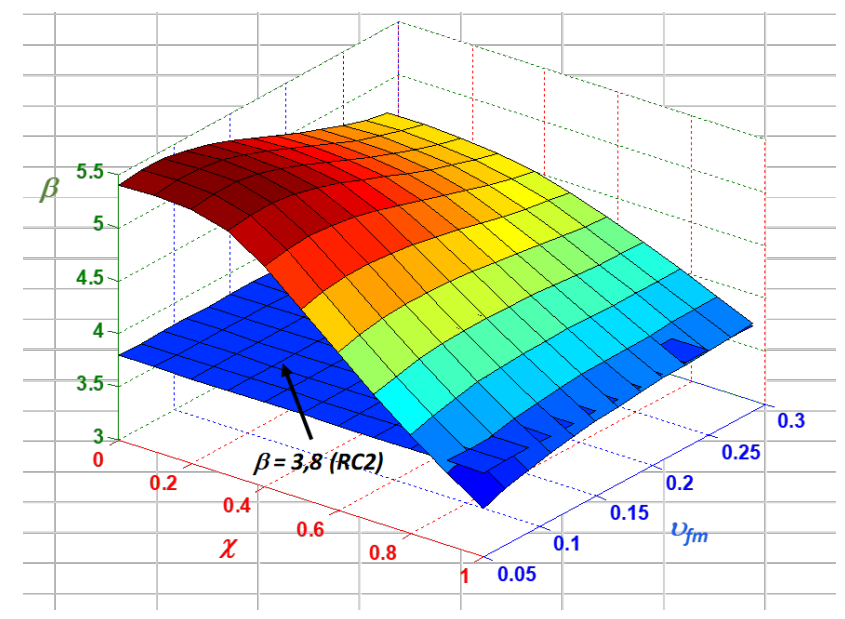

Figure 8: Area of relationship between the reliability index $\boldsymbol{\beta}$, the load coefficient $\chi$ and the coefficient of variation $v$ for the class $A$ execution of works and the combination of the norm coefficients according to formula $6.10 \mathrm{a}$ - reliability class RC2 


\section{Discussion}

The paper presents a study of the relationship between partial factors related to actions and partial factors for strength of masonry. First, an attempt was made to determine the level of safety in relation to the RC2 class of construction reliability. The results of the conducted analyses are presented in Figure 1, which show the relationship between the reliability index $\beta$ and the load factor $\chi$ for the class A execution of work and three different combinations of standard factors. A noticeable phenomenon is the decrease in the reliability level of the structure together with the increase in the share of variable action which is determined by twice the higher coefficient of variation for the variable action in relation to the permanent action. The graph contains reference lines defining the limit values of the reliability index for the RC2 class. In the case of a reference period of 50 years, i.e. the basic period for which the load-bearing capacity of the structure is determined, the reliability of 3.8 is ensured with a significant margin with respect to each of the three sets of partial factors to actions. An exception may be a situation when the share of variable action is approaching unity which is considered a phenomenon not practically in use. The recommendation from the literature of, eg, Prof. Holicki [5-7] is to limit the presented curves to the value of $\chi$ equal to 0.6 , because it is practically the largest possible occurrence of the load factor value. The second graph - Figure 2 was created by modifying the value of the compressive strength of masonry by applying a safety factor for the class B execution of the works. In this case, higher coefficient of variation for strength was also used. However, these modifications have not caused significant changes in the safety reserves.

Subsequent similar analyses were carried out designing the construction in the order of RC1 and RC3 reliability class respectively. Just as ECO recommends, only factors for actions are used. Figure 3 and Figure 4 relate first to the $\mathrm{RC} 1$ class. After the application of the decreasing factor to action equal to 0.9 , a significant safety margin was also noted for the reference period of 50 years. The situation looks a bit different in relation to the RC3 class, this time factor of 1.1 was applied according to the standard. Analysing the presented curves - Figure 5 and Figure 6 with reference to the straight line at the level of 4.3 , corresponding to the RC3 construction design for the reference period of 50 years, it was noticed that safety is only provided in the range of $\chi$ from 0 to 0.6 , which however, it can be considered sufficient. However, the question arises whether the use of only factors for actions in the design of structures in the RC1 and RC3 class is the correct approach. The graph Figure 8 confirms the convergence of the presented results on a relatively large range of variability of the coefficient of variation for the compressive strength of masonry $v \in(0,05 ; 0,30)$.

\section{Conclusions}

The analysis in this article may lead to the following conclusions:

- the safety margin when designing masonry structures in the RC2 reliability class in accordance with applicable standards $[3,4]$ is significant,

- it is possible to optimize the value of partial factors used in masonry structures according [3],

- designing masonry and other structures in the RC1 and RC3 reliability classes requires clarification of the rules contained in applicable norms.

\section{References}

[1] Drobiec $t$, Jasiński R, Piekarczyk A. "Masonry structures according to Eurocode 6 and related standards", vol. 2, chapter Fundamentals of Designing Structures, PWN, Warsaw, 2013

[2] Brehm E, Shelley L. Lissel "Reliability of unreinforced masonry bracing walls", $15^{\text {th }}$ International Brick and Block Masonry Conference, Florianópolis - Brazil - 2012

[3] EN 1996-1-1:2004 Eurocode 6: Design of masonry structures Part 1-1: General rules for reinforced and unreinforced masonry structures. 2004 CEN.

[4] EN 1990:2002 Eurocode - Basis of structural design. 2002 CEN.

[5] Holicky M, Markova J. Verification of load factors for concrete components by reliability and optimization analysis: background documents fot implementing Eurocodes. Prog Struct Eng Mater. 2000;2(4):502-7.

[6] Holicky M, Retief JV. Reliability assesssment of alternative Eurocode and South African load combination schemes fot structural design. Journal of and South African Institution of Civil Engeenering. 2005 Jan;47(1):15-20.

[7] Holicky M. Reliability analysis for structural design. Sun Press; 2009. https://doi.org/10.18820/9781920689346.

[8] Skrzypczak I. Buda - Ożóg L., Kujda J. (Zięba), “The impact of the quality of materials on the differentiation of the reliability of a reinforced concrete beam", MATEC Web Conf., Volume 262, 2019.

[9] Kujda J. (Zięba), "Analysis of limit state of load resistance and reliability of masonry structures made of AAC blocks", MATEC Web Conf., Volume 262, 2019.

[10] Buda- Ożóg Lidia L., Raczak A., Skrzypczak I., Szylak K., “MASONRY CONSTRUCTIONS. Examples of calculations according to Eurocode 6 and probabilistic methods", Rzeszow, 2017 PNISO 2394: General principles of reliability of building structures, 2010 
[11] Woliński Sz.: "Calibration of partial coefficients for existing structures”, Scientific notebooks PRz 2011, in Polish
[12] Woliński S, Wróbel K. Reliability of building structures. Rzeszow; 2001. [in Polish]. 